\title{
Multi-Input Converter with MPPT Feature for Wind-PV Power Generation System
}

\author{
Chih-Lung Shen and Shih-Hsueh Yang \\ Department of Electronic Engineering, National Kaohsiung First University of Science and Technology, Nanzih, Kaohsiung 811, Taiwan \\ Correspondence should be addressed to Chih-Lung Shen; clshen@ccms.nkfust.edu.tw
}

Received 16 January 2013; Revised 1 April 2013; Accepted 20 April 2013

Academic Editor: Bhushan Sopori

Copyright ( 2013 C.-L. Shen and S.-H. Yang. This is an open access article distributed under the Creative Commons Attribution License, which permits unrestricted use, distribution, and reproduction in any medium, provided the original work is properly cited.

\begin{abstract}
A multi-input converter (MIC) to process wind-PV power is proposed, designed, analyzed, simulated, and implemented. The MIC cannot only process solar energy but deal with wind power, of which structure is derived from forward-type DC/DC converter to step-down/up voltage for charger systems, DC distribution applications, or grid connection. The MIC comprises an upper modified double-ended forward, a lower modified double-ended forward, a common output inductor, and a DSP-based system controller. The two modified double-ended forwards can operate individually or simultaneously so as to accommodate the variation of the hybrid renewable energy under different atmospheric conditions. While the MIC operates at interleaving mode, better performance can be achieved and volume also is reduced. The proposed MIC is capable of recycling the energy stored in the leakage inductance and obtaining high step-up output voltage. In order to draw maximum power from wind turbine and PV panel, perturb-and-observe method is adopted to achieve maximum power point tracking (MPPT) feature. The MIC is constructed, analyzed, simulated, and tested. Simulations and hardware measurements have demonstrated the feasibility and functionality of the proposed multi-input converter.
\end{abstract}

\section{Introduction}

Conventionally, electric power is mainly generated from fossil fuels. However, this kind of energy resources is highly limited and will be exhausted in the near future. With the rapid requirement of electricity and the increase of worse and worse energy crisis, it is of great urgency to replace the fossil fuels with renewable energy. Among the renewable resources, solar energy and wind power attract a great deal of interest owing to their easy acquirement.

In photovoltaic $(\mathrm{PV})$ or wind power generation system, a power converter is needed so as to process renewable energy. In literature [1-5] PV converters are presented while wind power converters are studied in [6-10]. However, these power converters only handle a single kind of renewable energy, that is, which cannot deal with multi-input power. Therefore, some researchers propose multi-input converters for solarwind hybrid power generation system. As shown in Figure 1, a series double-boost converter is presented to process $\mathrm{PV}$ power and wind energy simultaneously [11], in which, as compared with single-boost configuration, power component only imposes one-half power rating. Even though this boosttype converter steps up the voltage and is suitable for a high voltage supply, it cannot be applied to galvanic isolated applications. Double-input buck-boost converter shown in Figure 2 is capable of processing high-/low-voltage sources [12]. Like boost-type converter, this type of configuration is still nonisolated electrically. Instead of combining renewable energy in electricity, the concept of magnetic flux additivity is proposed to design a multi-input isolated converter, as shown in Figure 3, but its structure is complex and control low is complicated [13]. In order to simplify power-stage configuration, the forward-derived configuration is proposed. However, it cannot trap the energy in the leakage inductor and is incapable of applying to high output voltage applications [14].

In this paper, a multi-input converter (MIC) is proposed, which can not only deal with PV power and windturbine energy simultaneously/individually but recycles the leakage-inductance energy and steps up the input voltage. As compared with the aforementioned isolated double-input converter, the proposed one has a much simpler structure. 


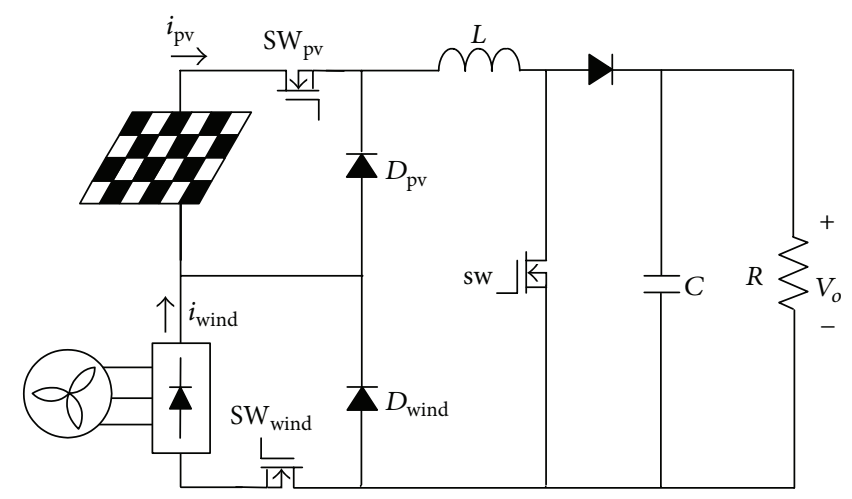

FIgURE 1: An illustration of double-boost converter for wind-PV system.

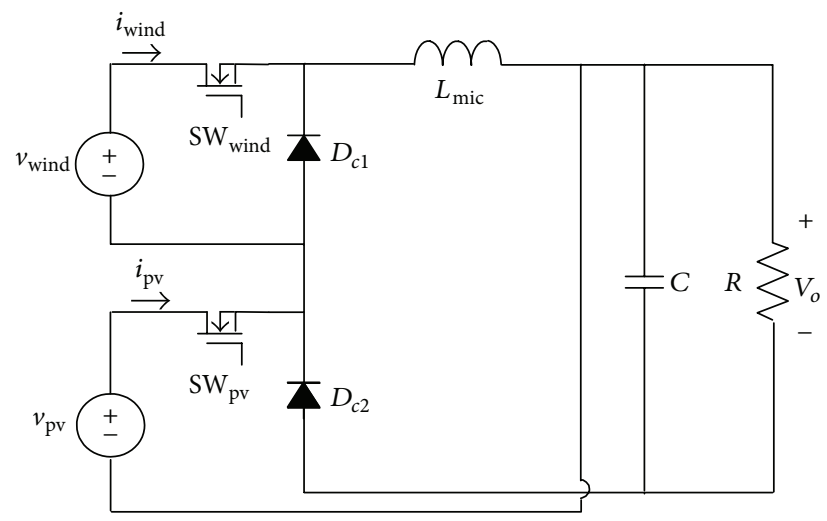

FIGURE 2: An illustration of double-input buck-boost converter.

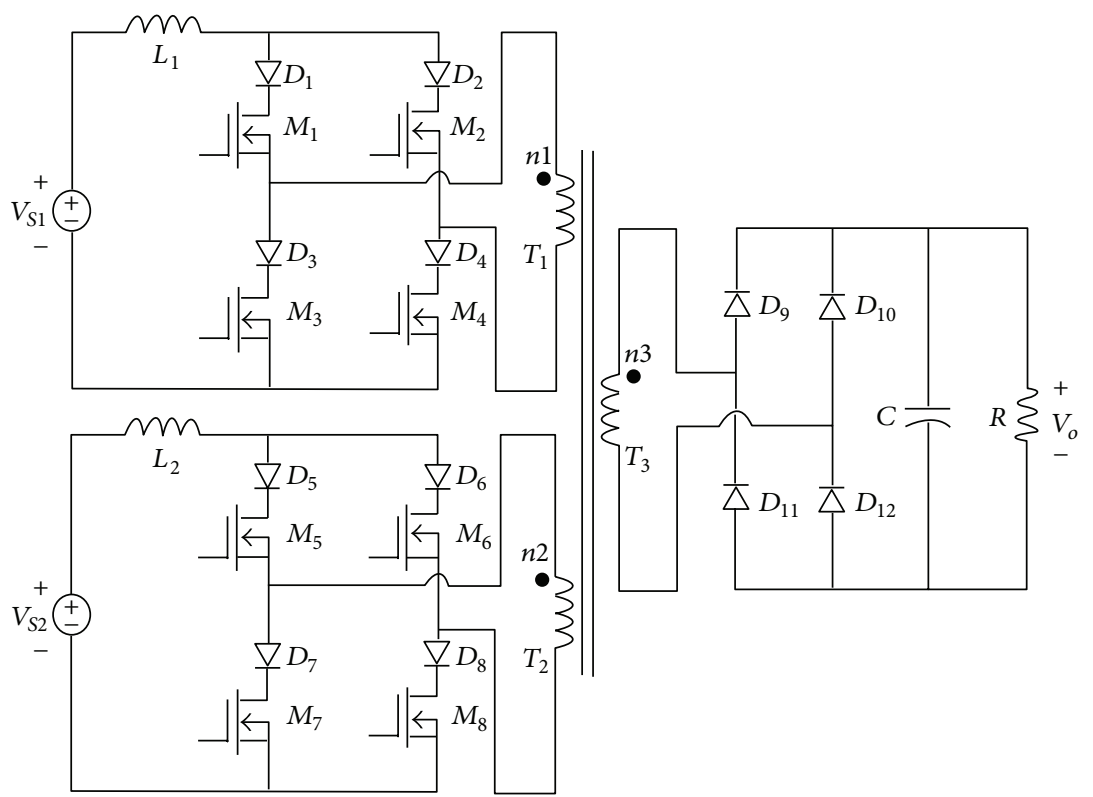

FIGURE 3: An illustration of multi-input converter based on magnetic flux additivity.

Furthermore, the proposed MIC removes the third winding from the conventional forward converter, which releases the energy stored in the magnetizing inductor to a capacitor through the second winding. As a result, its output voltage can be stepped up significantly and the efficiency is improved.
Simulated and practical results have validated the proposed PV-wind MIC.

In this paper, system architecture of the proposed MIC is described in Section 2. Section 3 presents the operational principle of the converter, while simulations and practical 


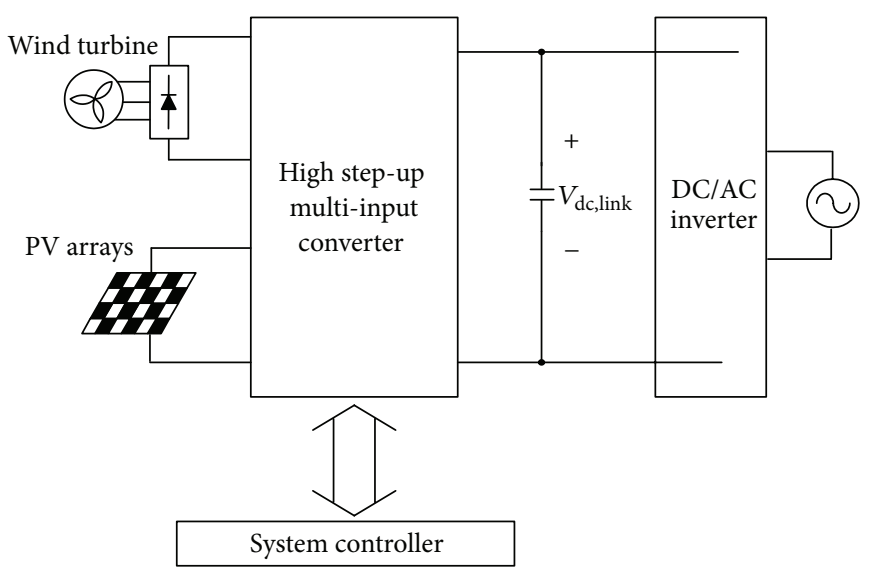

FIGURE 4: A block diagram to represent the configuration of the proposed MIC.

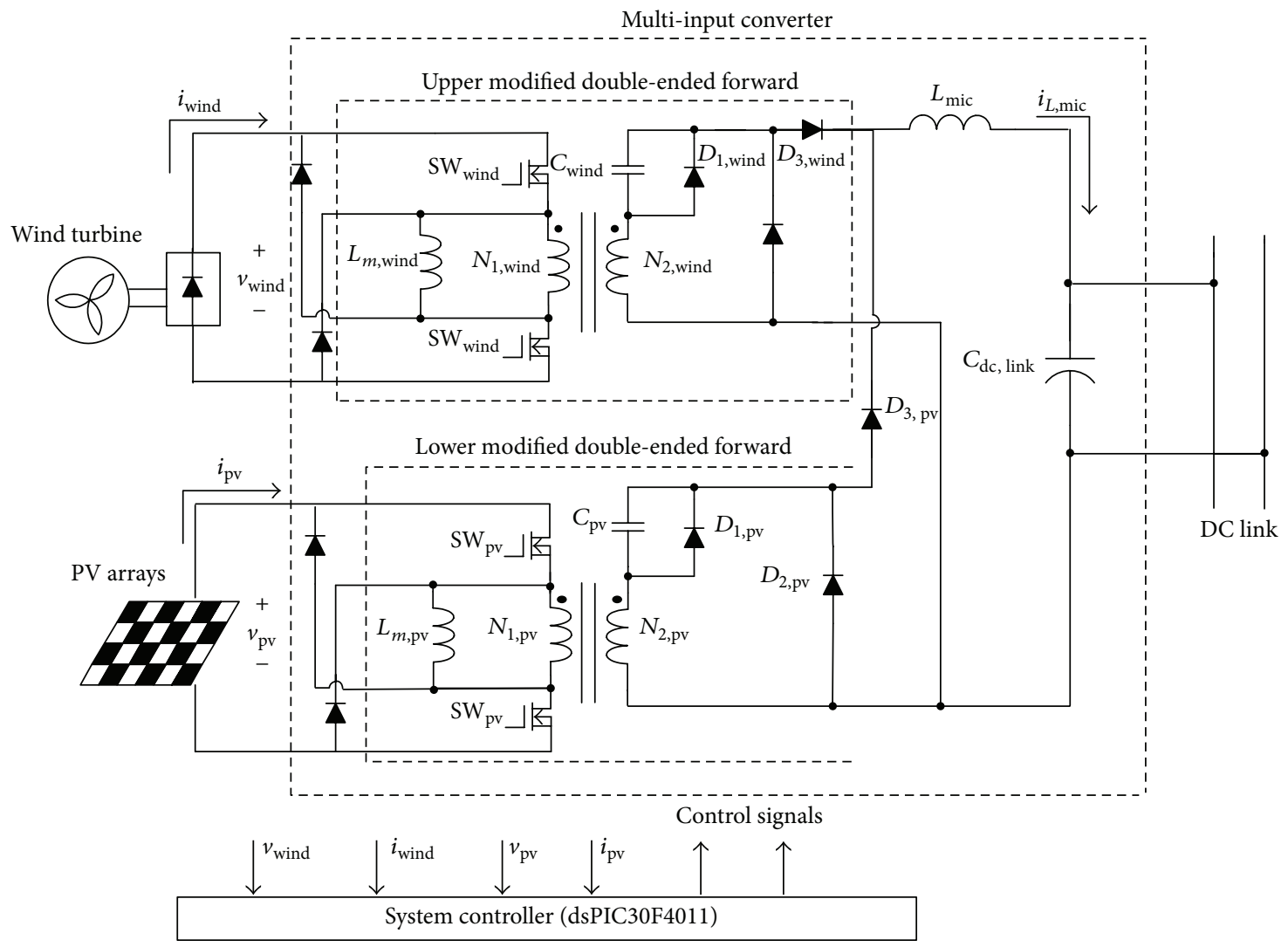

FIgURE 5: The proposed multi-input converter to process PV-wind power.

measurements to verify the feasibility of the MIC are shown in Section 4. Finally, conclusion is given in Section 5.

\section{Configuration of the Proposed Converter}

Figure 4 illustrates the block diagram of the proposed MIC, which mainly includes PV arrays, a wind turbine, a high stepup multi-input converter, and a system controller. Figure 5 shows the corresponding schematics of the main power stage of the MIC. In Figure 5, the MIC is composed of an upper modified double-ended forward, a lower modified doubleended forward, a common output filter $L_{\text {mic }}$, and a system controller. The upper modified double-ended forward is in charge of dealing with wind-turbine energy while the lower one processes solar power. The both modified double-ended forwards can be operated independently, which expands the degree of control freedom. The active switches in the upper forward or in the lower one are switched synchronously so as to trap the leakage energy and to release the magnetizing inductance energy. The capacitors in the secondary windings, $C_{\text {wind }}$ and $C_{\mathrm{pv}}$, will absorb the energy of magnetizing 


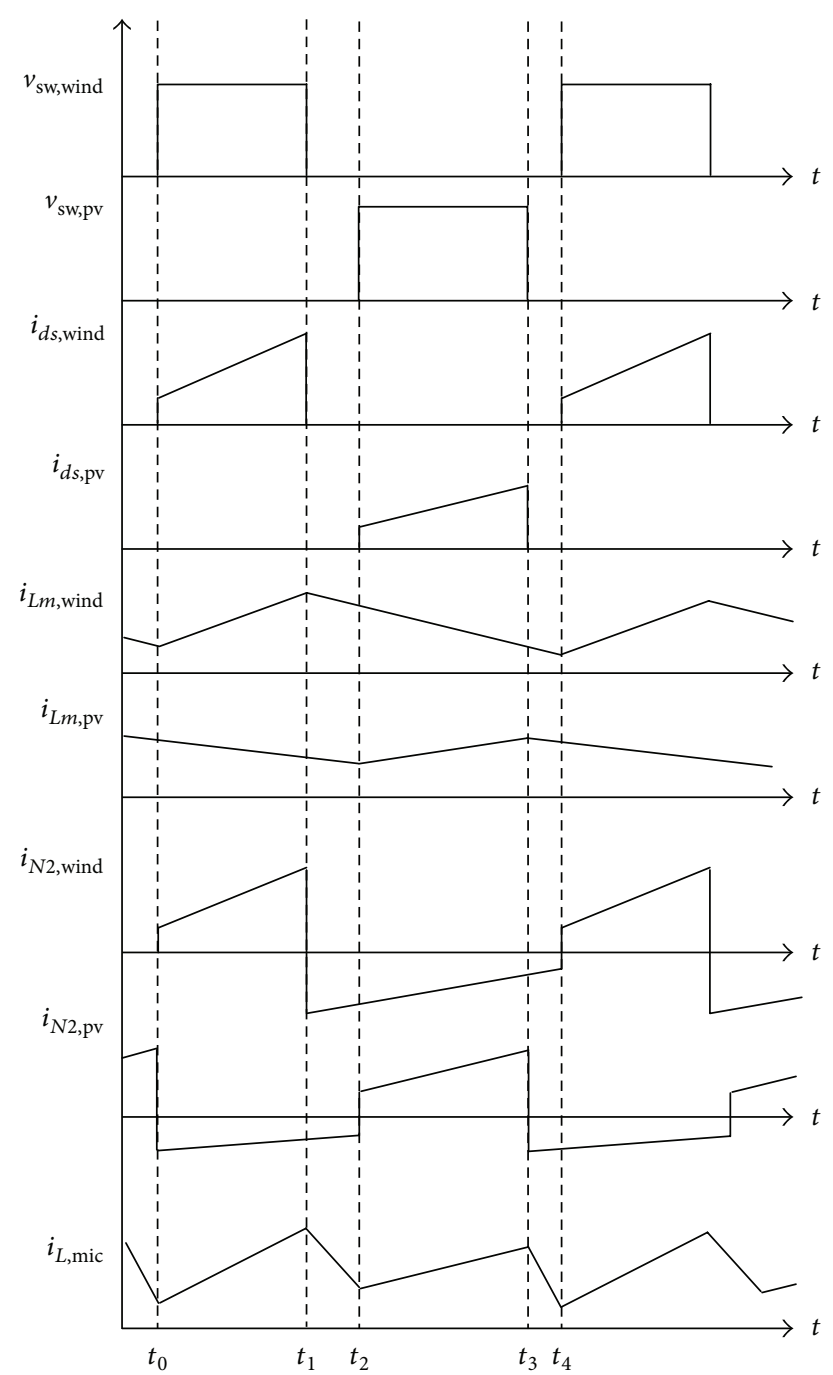

FIGURE 6: Conceptual key waveforms of the proposed MIC.

inductance and then can boost the output voltage. The system controller determines the control signals to perform output power controlling and maximum power point tracking (MPPT). In this paper, perturb-and-observe method is adopted for MPPT.

\section{Operation Principle of the Proposed Converter}

In Figure 5 the two modified double-ended forwards can operate individually to deal with PV power and wind energy. To achieve better output performance and to lower the output filter volume, the switches $\mathrm{SW}_{\text {wind }}$ and $\mathrm{SW}_{\mathrm{pv}}$ are turned on alternatively with a duty ratio less than 0.5 at the same switching frequency. Figure 5 shows conceptual key waveforms. According to the conduction status of the switches $\mathrm{SW}_{\text {wind }}$ and $\mathrm{SW}_{\mathrm{pv}}$, the operation of the MIC over one switching period can be mainly divided into four modes. Corresponding equivalents are presented in Figure 6. Each operation mode is described in the following.
Mode 1 (Figure 7(a), $t_{0} \leq t<t_{1}$ ). During the interval of Mode 1 , the status of switches $\mathrm{SW}_{\text {wind }}$ is on but $\mathrm{SW}_{\mathrm{pv}}$ off. While $S W_{\text {wind }}$ conducts at $t_{0}$, this mode begins. The active switch $\mathrm{SW}_{\mathrm{pv}}$ is in the off-state, and the magnetizing inductor of the lower modified forward discharges energy through the path of $N_{2, \mathrm{pv}}-D_{2, \mathrm{pv}}-C_{\mathrm{pv}}$. Meanwhile, wind power is forwarded to output. Therefore, $i_{L, \text { mic }}$ is linearly built and can be described as

$$
i_{L, \text { mic }}(t)=\frac{2 \cdot N_{\text {wind }} \cdot k_{\text {wind }} \cdot v_{\text {wind }}}{L_{\text {mic }}} \cdot D_{\text {wind }} \cdot \frac{T_{s}}{2}+i_{L, \text { mic }}\left(t_{0}\right),
$$

where $k_{\text {wind }}$ is the coupling coefficient of the transformer in the upper forward, $D_{\text {wind }}$ stands for duty ratio of $S W_{\text {wind }}$, and $T_{s}$ represents the switching period. The voltage stresses of the switch $\mathrm{SW}_{\mathrm{pv}}$ and diode $D_{2 \text {,wind }}$ can be found by

$$
\begin{gathered}
v_{D S, \mathrm{pv}}=v_{\mathrm{pv}} \\
v_{D 2, \text { wind }}=2 \cdot N_{\text {wind }} \cdot k_{\text {wind }} \cdot v_{\text {wind }} .
\end{gathered}
$$




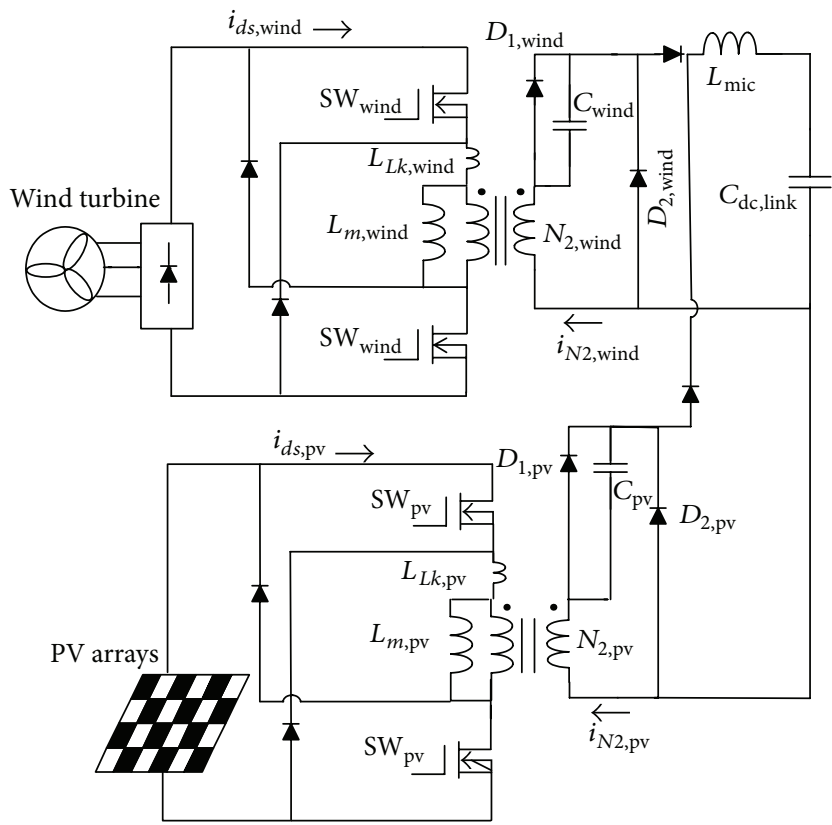

(a)

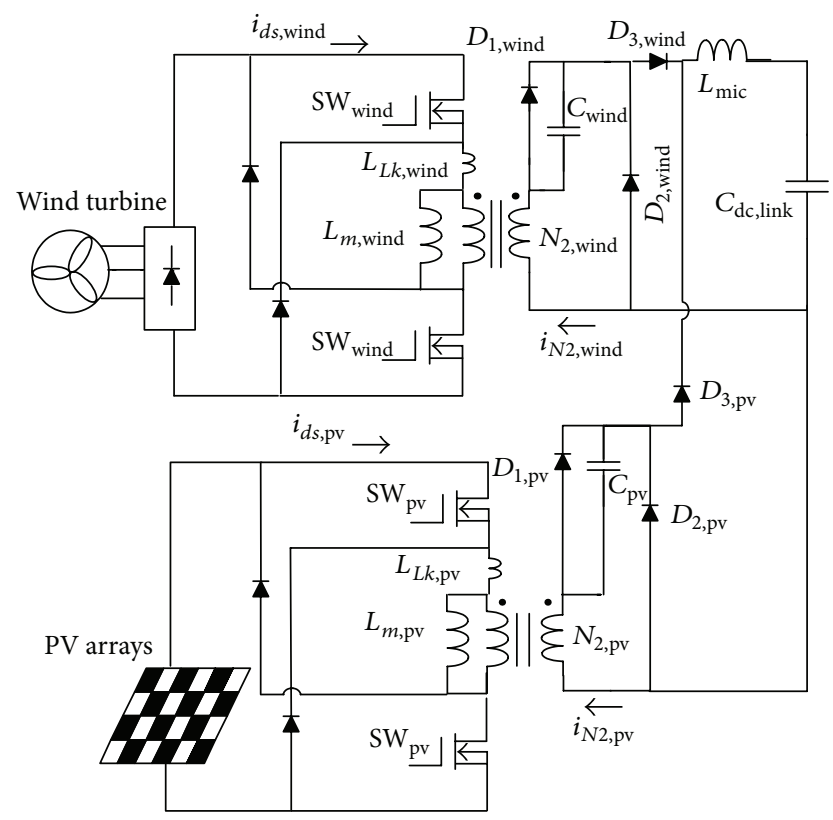

(c)

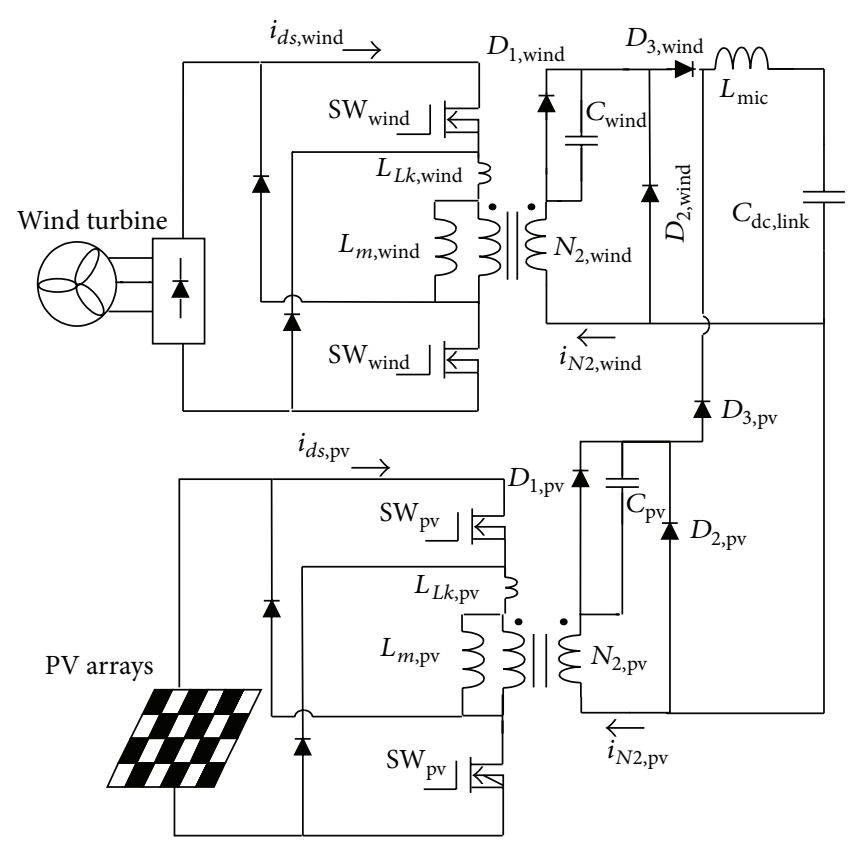

(b)

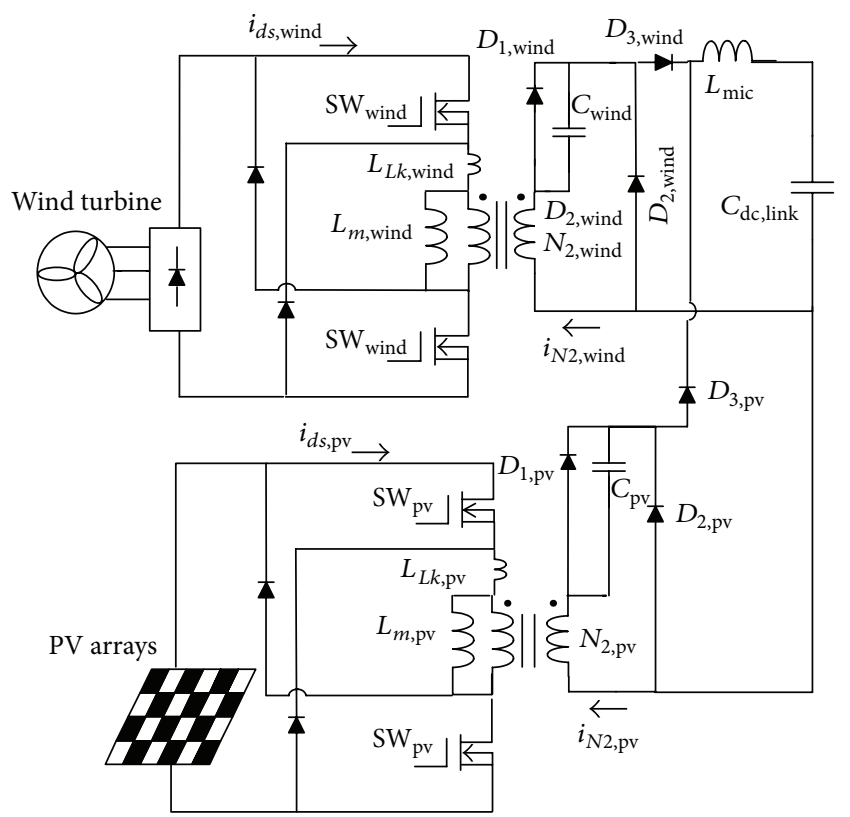

(d)

FIGURE 7: Equivalent circuits of the MIC corresponding to the four operation modes over one switching cycle: (a) Mode 1, (b) Mode 2, (c) Mode 3, and (d) Mode 4.

As the current of magnetizing inductor $L_{m, \mathrm{pv}}$ drops to zero, this mode ends.

Mode 2 (Figure 7(b), $t_{1} \leq t<t_{2}$ ). In Mode 2, all the active switches are in off-state. At time $t_{1}$, the switch $\mathrm{SW}_{\text {wind }}$ is turned off and $\mathrm{SW}_{\mathrm{pv}}$ in the lower forward still stays in the offstate. The magnetizing inductor in the upper modified forward $L_{m \text {,wind }}$ discharges via the path of $N_{2 \text {,wind }}-D_{2 \text {,wind }}-C_{\text {wind }}$, while the energy of leakage inductor $L_{L K \text {,wind }}$ is trapped.
The voltages across $C_{\text {wind }}$ and $C_{\mathrm{pv}}, v_{c \text {,wind }}$ and $v_{c, \mathrm{pv}}$, are obtained by

$$
\begin{gathered}
v_{c, \text { wind }}=N_{\text {wind }} \cdot k_{\text {wind }} \cdot v_{\text {wind }}, \\
v_{c, \mathrm{pv}}=N_{\mathrm{pv}} \cdot k_{\mathrm{pv}} \cdot v_{\mathrm{pv}},
\end{gathered}
$$

respectively, in which $k_{\mathrm{pv}}$ is the coupling coefficient of the transformer in the lower forward. In addition, the output inductor $L_{\text {mic }}$ releases the stored energy to the load by 




FIGURE 8: The waveform of output inductor current.

the path of $L_{\text {mic }}-C_{\mathrm{dc} \text {,link }}-D_{2 \text {,wind }}$, of which the current is linearly decreased and is expressed as

$$
i_{L, \text { mic }}(t)=i_{L, \text { mic }}\left(t_{1}\right)-\frac{V_{\mathrm{dc}, \text { link }}}{L_{\text {mic }}} \cdot D_{\text {wind }} \cdot \frac{T_{s}}{2} \cdot\left(1-D_{\text {wind }}\right) \text {. }
$$

Mode 3 (Figure 7(c), $t_{2} \leq t<t_{3}$ ). During this mode, $\mathrm{SW}_{\mathrm{pv}}$ is in the on-state but $\mathrm{SW}_{\text {wind }}$ in off-state. Since the $\mathrm{SW}_{\mathrm{pv}}$ is turned on at $t_{2}$, thus PV energy is dealt with by the lower modified forward. The inductor current $i_{L \text {,mic }}$ increases linearly. The inductor $L_{m \text {,wind }}$ releases the energy to the capacitor $C_{\text {wind }}$ through the path of $N_{2 \text {,wind }}-D_{2 \text {,wind }}-C_{\text {wind }}$. In this interval, the current of output inductor $L_{\text {mic }}$ is linearly built and can be described as

$$
i_{L, \text { mic }}(t)=\frac{2 \cdot N_{\mathrm{pv}} \cdot k_{\mathrm{pv}} \cdot v_{\mathrm{pv}}}{L_{\mathrm{mic}}} \cdot D_{\mathrm{pv}} \cdot \frac{T_{s}}{2}+i_{L, \text { mic }}\left(t_{2}\right),
$$

where $D_{\mathrm{pv}}$ denotes the duty ratio of $\mathrm{SW}_{\mathrm{pv}}$. The voltage stresses of the switch $\mathrm{SW}_{\mathrm{pv}}$ and diode $D_{2 \text {,wind }}$ can be expressed as follows:

$$
\begin{gathered}
v_{D S, \text { wind }}=v_{\text {wind }}, \\
v_{D 2, \mathrm{pv}}=2 \cdot N_{\mathrm{pv}} \cdot k_{\mathrm{pv}} \cdot v_{\mathrm{pv}} .
\end{gathered}
$$

This mode ends at the moment the current flowing through $L_{m \text {,wind }}$ equals zero.

Mode 4 (Figure 7(d), $t_{3} \leq t<t_{4}$ ). At time $t_{3}$, the switch $\mathrm{SW}_{\mathrm{pv}}$ is turned off and the operation of the MIC enters into Mode 4. That is, in Mode 4 all active switches are off. During this mode, the magnetizing inductor $L_{m, \mathrm{pv}}$ releases energy to capacitor $C_{\mathrm{pv}}$ via $N_{2, \mathrm{pv}}, D_{2, \mathrm{pv}}$, and $C_{\mathrm{pv}}$. In addition, the energy stored in leakage inductance is recycled. Meanwhile, the output inductor discharges and the current $i_{L \text {,mic }}$ decreases linearly, which can be expressed as

$$
i_{L, \text { mic }}(t)=i_{L, \text { mic }}\left(t_{3}\right)-\frac{V_{\mathrm{dc}, \text { link }}}{L_{\text {mic }}} \cdot D_{\mathrm{pv}} \cdot \frac{T_{s}}{2} \cdot\left(1-D_{\mathrm{pv}}\right) .
$$

A complete switching cycle is terminated at $t=t_{4}$, at which $\mathrm{SW}_{\text {wind }}$ is turned on again.

While the proposed MIC operates in continuous conduction mode (CCM), the corresponding waveform of output inductor current is illustrated in Figure 8. The $T_{s}$ is the switching period and can be expressed as

$$
T_{s, \text { wind }}+T_{s, \mathrm{pv}}=T_{s} \text {. }
$$

In (8), $T_{s \text {,wind }}$ stands for the intervals that the upper modified forward works, while $T_{s, \mathrm{pv}}$ for the lower modified forward. In the interleaved operation, the following relationship holds:

$$
T_{s, \mathrm{pv}}=T_{s, \text { wind }}=\frac{T_{s}}{2} .
$$

Based on volt-second balance criterion, one can obtain the following identity:

$$
\begin{aligned}
(2 & \left.N_{\text {wind }} \cdot k_{\text {wind }} \cdot v_{\text {wind }}-V_{\mathrm{dc}, \text { link }}\right) \cdot D_{\text {wind }} \cdot T_{s, \text { wind }} \\
& +\left(2 \cdot N_{\mathrm{pv}} \cdot k_{\mathrm{pv}} \cdot v_{\mathrm{pv}}-V_{\mathrm{dc}, \text { link }}\right) \cdot D_{\mathrm{pv}} \cdot T_{s, \mathrm{pv}} \\
= & \left(1-D_{\text {wind }}\right) \cdot T_{s, \text { wind }} \cdot V_{\mathrm{dc}, \text { link }}+\left(1-D_{\mathrm{pv}}\right) \cdot T_{s, \mathrm{pv}} \cdot V_{\mathrm{dc}, \text { link }}
\end{aligned}
$$

Rearranging (10) yields

$$
V_{\mathrm{dc} \text {,link }}=N_{\text {wind }} \cdot k_{\text {wind }} \cdot v_{\text {wind }} \cdot D_{\text {wind }}+N_{\mathrm{pv}} \cdot k_{\mathrm{pv}} \cdot v_{\mathrm{pv}} \cdot D_{\mathrm{pv}} \text {, }
$$

which reveals that the DC-link voltage can be controlled by the duty ratios of $\mathrm{SW}_{\text {wind }}$ and $\mathrm{SW}_{\mathrm{pv}}$.

In the MIC, perturb-and-observe method is employed to draw maximum power from wind turbine and PV arrays since it is easy to carry out. The perturb-and-observe MPPT is realized by dsPIC30F4011. The related flowchart is presented in Figure 9.

\section{Simulations and Practical Measurements}

To demonstrate the feasibility of the proposed MIC, a prototype is constructed, simulated, and tested. Important parameters are listed as follows:

(i) PV panel voltage: $v_{\mathrm{pv}}=40-56 \mathrm{~V}$,

(ii) wind turbine voltage: $v_{\text {wind }}=22-48 \mathrm{~V}$,

(iii) dc-link voltage: $200 \mathrm{~V}$,

(iv) upper modified double-ended forward: $350 \mathrm{~W}$,

(v) lower modified double-ended forward: $350 \mathrm{~W}$,

(vi) switching frequency: $50 \mathrm{kHz}$ for all active switches,

(vii) output inductance: $L_{\text {mic }}=400 \mu \mathrm{H}$,

(viii) output capacitance: $C_{\mathrm{dc}, \text { link }}=400 \mu \mathrm{F}$, 


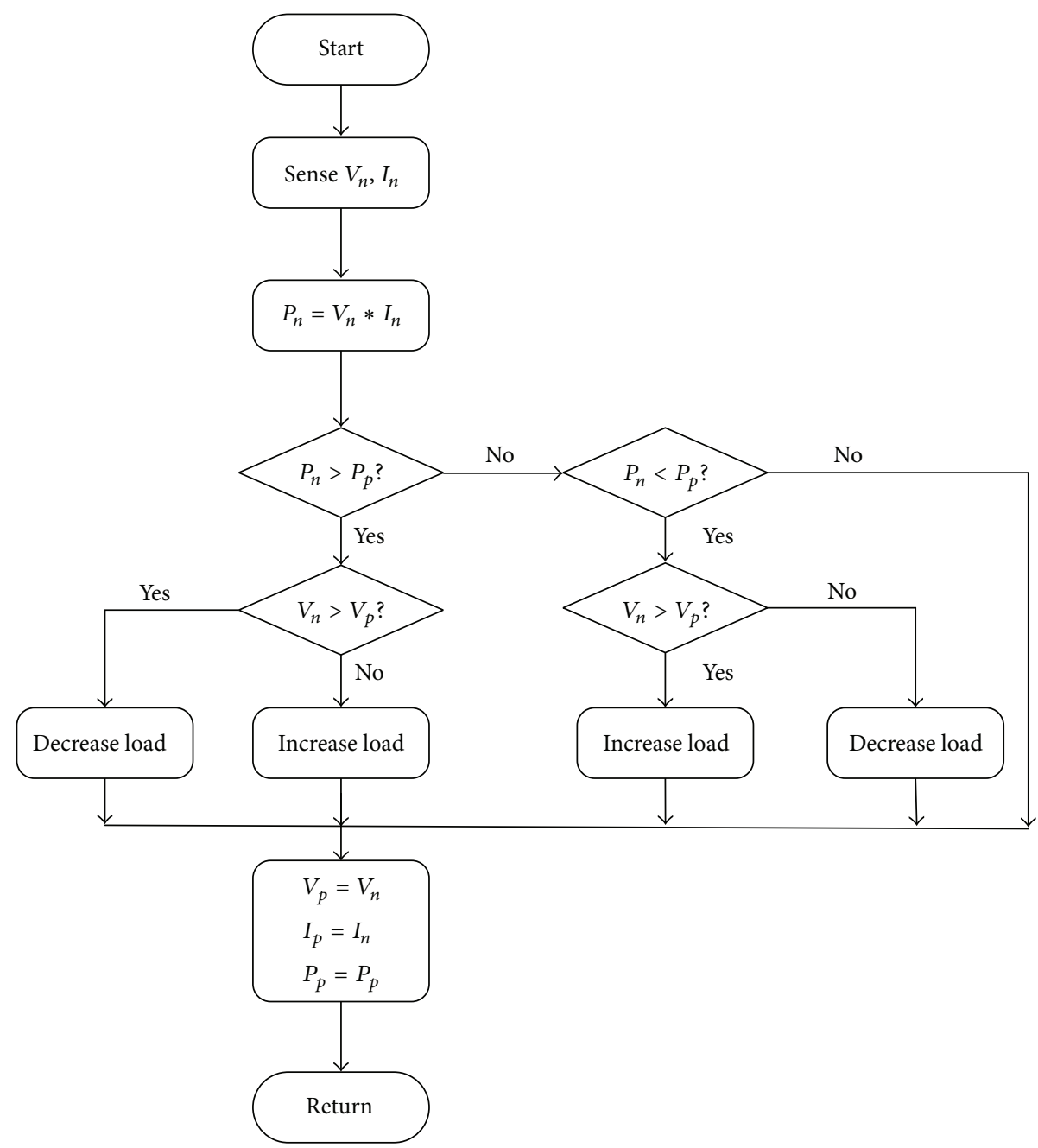

FIGURE 9: The flowchart of perturb-and-observe method to achieve MPPT feature.

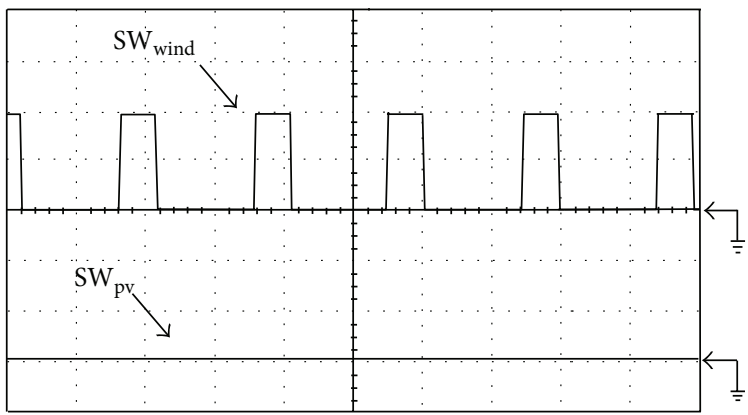

(Voltage: $5 \mathrm{~V} /$ div, time: $10 \mu \mathrm{s} /$ div)

FIGURE 10: Simulated control signals while wind turbine provides $350 \mathrm{~W}$.

(ix) capacitance of upper forward: $C_{\text {wind }}=22 \mu \mathrm{F}$,

(x) capacitance of lower forward: $C_{\mathrm{pv}}=22 \mu \mathrm{F}$.

In the case of only wind turbine providing $350 \mathrm{~W}$, the simulated active switch signals and corresponding output inductor current are shown in Figures 10 and 11, respectively, while Figures 12 and 13 are the practical measurements. With the perturb-and-observe method for maximum power point tracking, the measured result is shown in Figure 14, which has illustrated that the upper modified double-ended forward can draw the maximum power from wind turbine. If only 350 W PV power feeds the MIC, simulations of control signals for active switches and output inductor current are presented in Figures 15 and 16. In addition, Figures 17 and 18 are the 


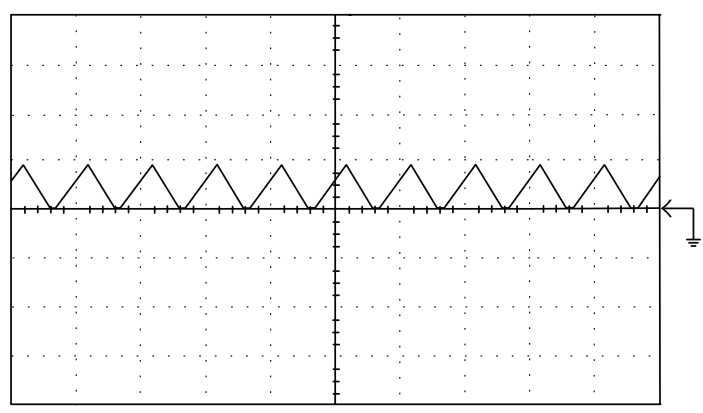

(Current: $5 \mathrm{~A} / \mathrm{div}$, time: $20 \mu \mathrm{s} / \mathrm{div}$ )

FIGURE 11: Simulated output inductor current while wind turbine provides $350 \mathrm{~W}$.

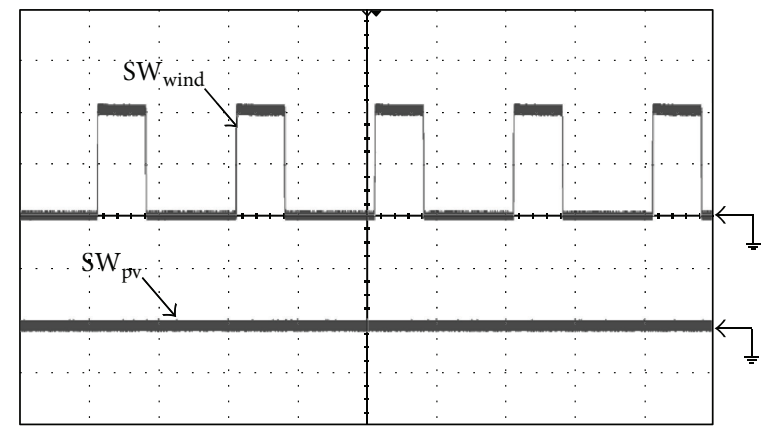

(Voltage: $5 \mathrm{~V} /$ div, time: $10 \mu \mathrm{s} /$ div)

FIGURE 12: Practical measurements of control signals while wind turbine provides $350 \mathrm{~W}$.

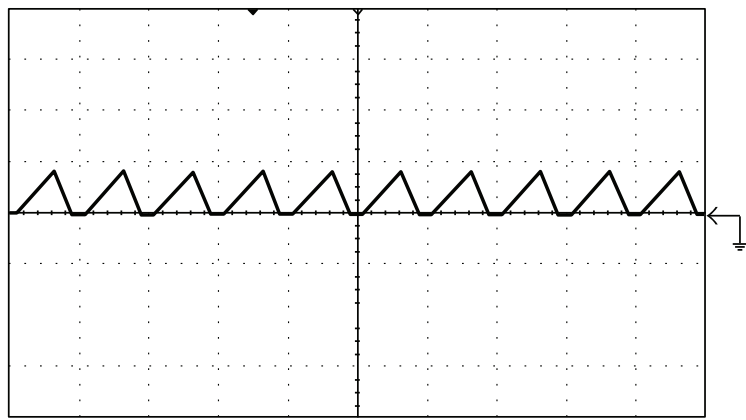

(Current: $5 \mathrm{~A} /$ div, time: $20 \mu \mathrm{s} / \mathrm{div}$ )

FIGURE 13: Measured output inductor current while wind turbine provides $350 \mathrm{~W}$.

measured results. For MPPT feature verification, Figure 19 is the relationship between PV power and the terminal voltage of PV panel, from which it can be found that the proposed MIC is able to draw maximum power from PV panel. From Figures 10-19, it has been demonstrated that the proposed MIC is capable of dealing with individual renewable power. As the solar power and wind energy feed the MIC simultaneously, Figures 20 and 21 show the simulations of control signals and output inductor current. Then, Figures 22 and 23 present the hardware measurements. In addition, switch currents are also shown in Figure 24, in which the upper trace and the lower trace are the drain-to-source currents of $\mathrm{SW}_{\text {wind }}$ and $\mathrm{SW}_{\mathrm{pv}}$, respectively. Figure 25 is the hardware measurements of the secondary currents $i_{N 2 \text {,wind }}$ and $i_{N 2 \text {,pv }}$. All the experimental results correspond with the theoretical waveforms in Figure 6. From Figures 20-25, it is verified that the MIC not only can process hybrid wind-PV power but can operate in interleaved mode for current ripple suppression. Additionally, in Figures 21 and 23, the ripple of output inductor current is double the switch frequency, which results in lower volume requirement for output filter inductor. The measured efficiency of the MIC is shown in Figure 26. In the case of wind turbine shutting down from the hybrid power generation system, the output power variation of the MIC is shown in Figure 27. For converse condition, the related output power curve is shown in Figure 28. 


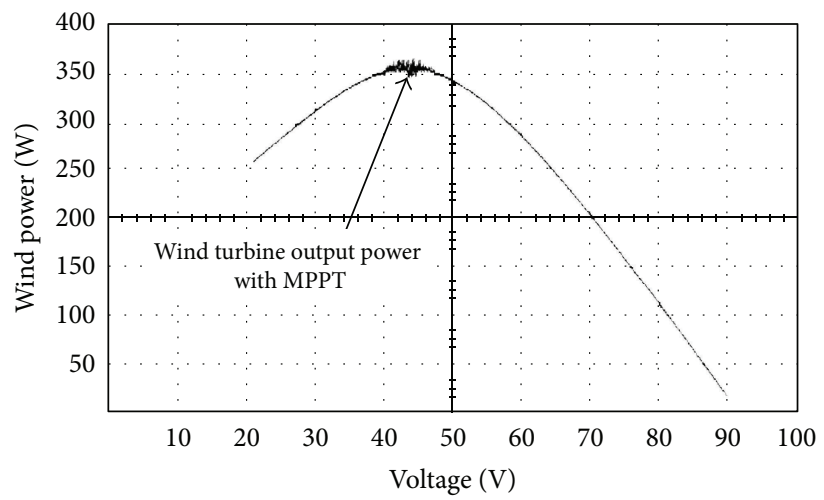

FIGURE 14: Measured result: drawn power from wind turbine with MPPT.

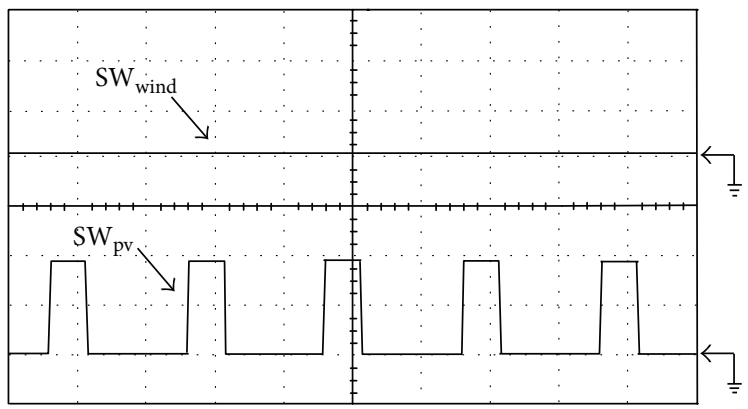

(Voltage: $5 \mathrm{~V} /$ div, time: $10 \mu \mathrm{s} /$ div)

FIGURE 15: Simulated control signals while PV panel provides $350 \mathrm{~W}$.

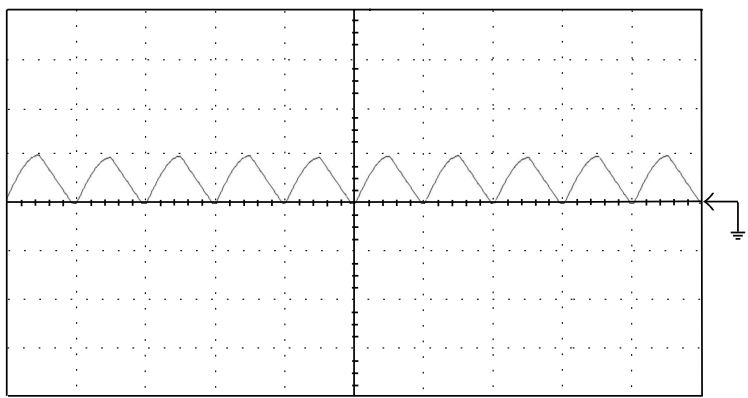

(Current: $5 \mathrm{~A} / \mathrm{div}$, time: $20 \mu \mathrm{s} / \mathrm{div}$ )

FIgURE 16: Simulated output inductor current while PV panel provides $350 \mathrm{~W}$.

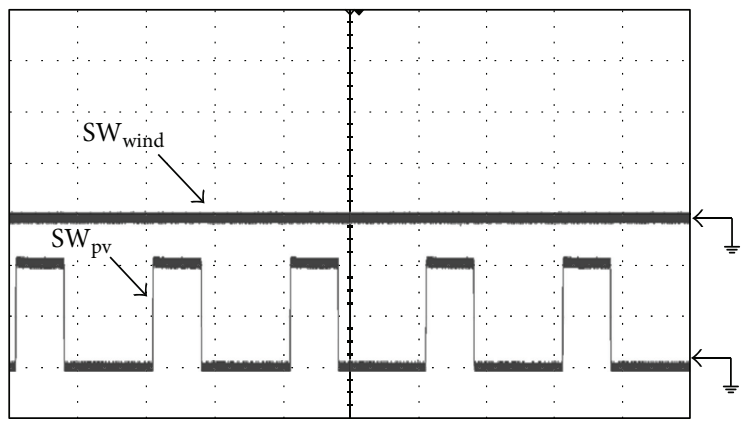

(Voltage: $5 \mathrm{~V} /$ div, time: $10 \mu \mathrm{s} /$ div)

FIGURE 17: Practical measurements of control signals while PV panel provides $350 \mathrm{~W}$. 


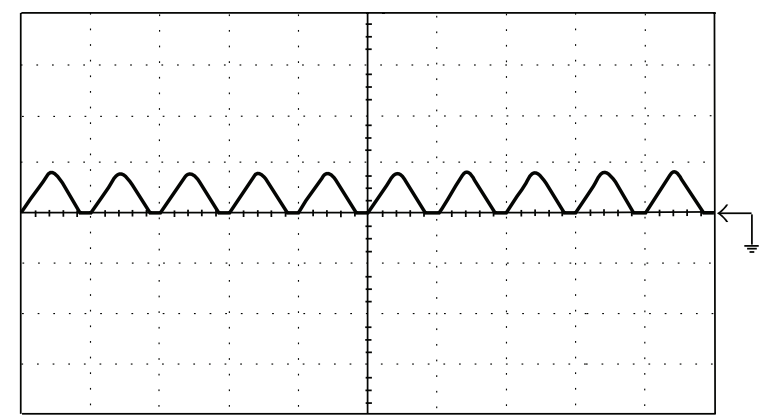

(Current: $5 \mathrm{~A} /$ div, time: $20 \mu \mathrm{s} / \mathrm{div}$ )

FIgURE 18: Measured output inductor current while PV panel provides $350 \mathrm{~W}$.

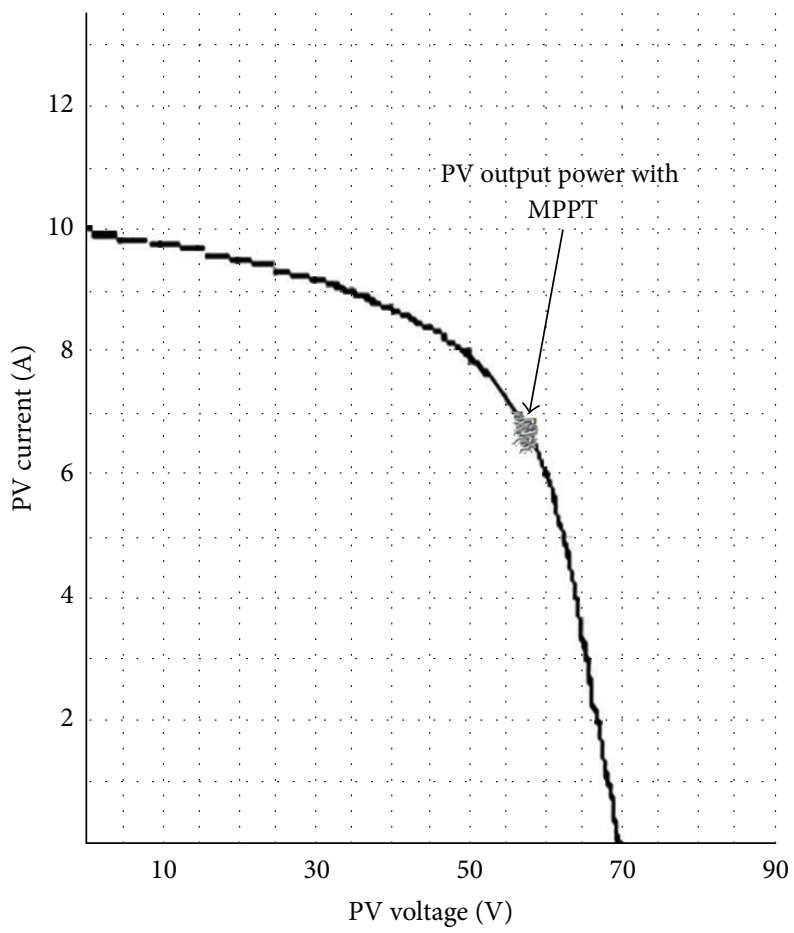

FIGURE 19: Measured result: operation point of PV panel after MPPT.

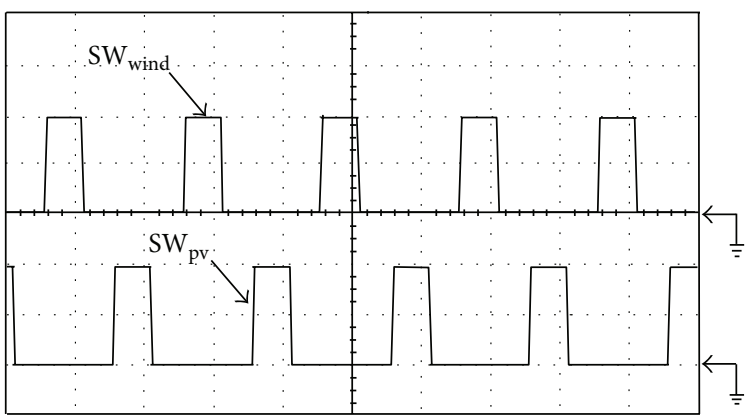

(Voltage: $5 \mathrm{~V} /$ div, time: $10 \mu \mathrm{s} / \mathrm{div}$ )

FIGURE 20: Simulated control signals while hybrid wind-PV power is $700 \mathrm{~W}$. 


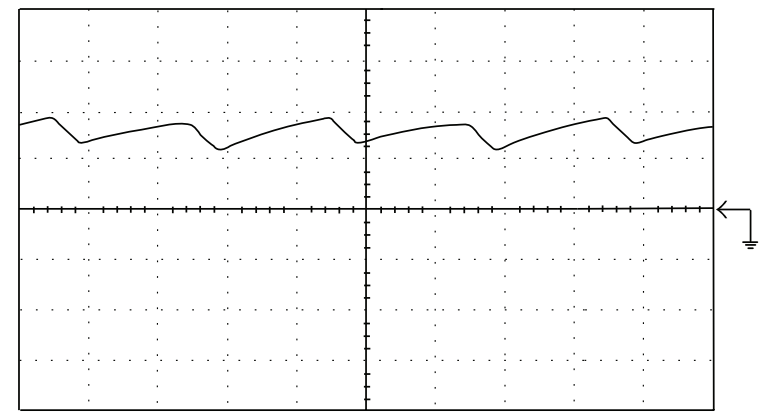

(Current: $2 \mathrm{~A} / \mathrm{div}$, time: $5 \mu \mathrm{s} / \mathrm{div}$ )

FIGURE 21: Simlated output inductor current while hybrid wind-PV power is $700 \mathrm{~W}$.

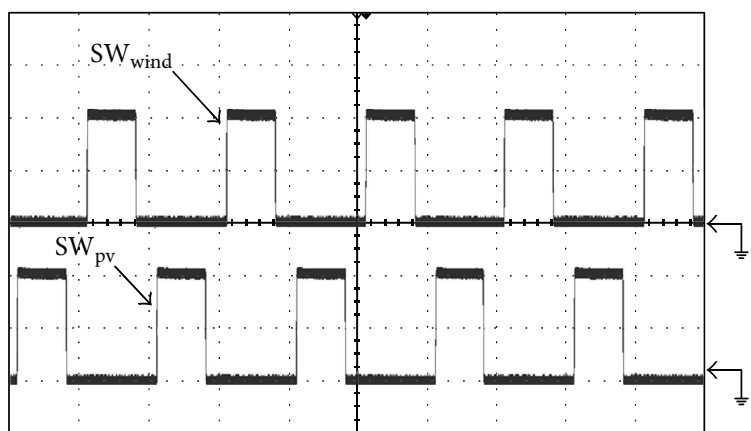

(Voltage: $5 \mathrm{~V} /$ div, time: $10 \mu \mathrm{s} / \mathrm{div}$ )

FIGURE 22: Measured control signals while hybrid wind-PV power is $700 \mathrm{~W}$.

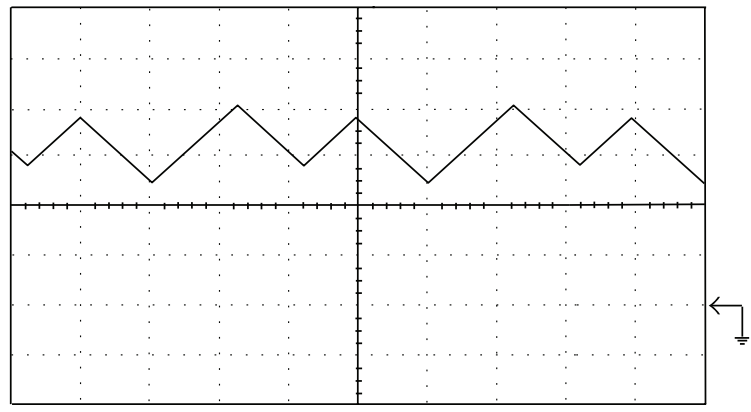

(Current: $1 \mathrm{~A} / \mathrm{div}$, time: $5 \mu \mathrm{s} / \mathrm{div}$ )

FIgURE 23: Measured output inductor current while hybrid wind-PV power is $700 \mathrm{~W}$.

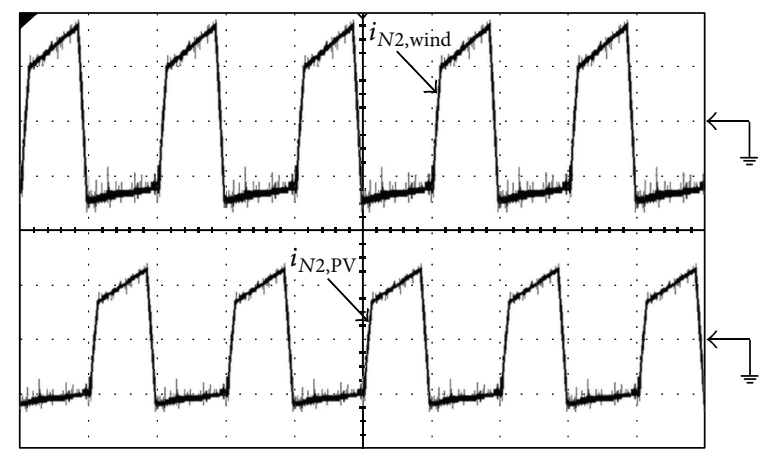

(Current: $2 \mathrm{~A} / \mathrm{div}$, time: $10 \mu \mathrm{s} / \mathrm{div}$ )

FIGURE 24: Measured waveforms of switch currents. 


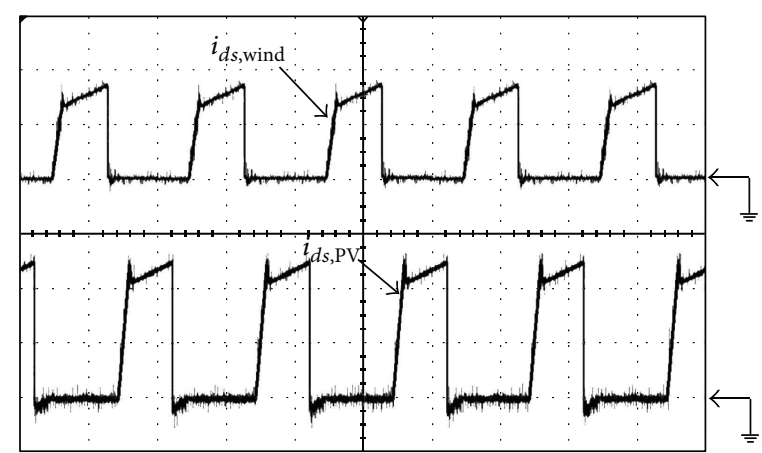

(Current: $10 \mathrm{~A} / \mathrm{div}$, time: $10 \mu \mathrm{s} / \mathrm{div}$ )

FiguRE 25: Measured current waveforms of the secondary windings in the MIC.

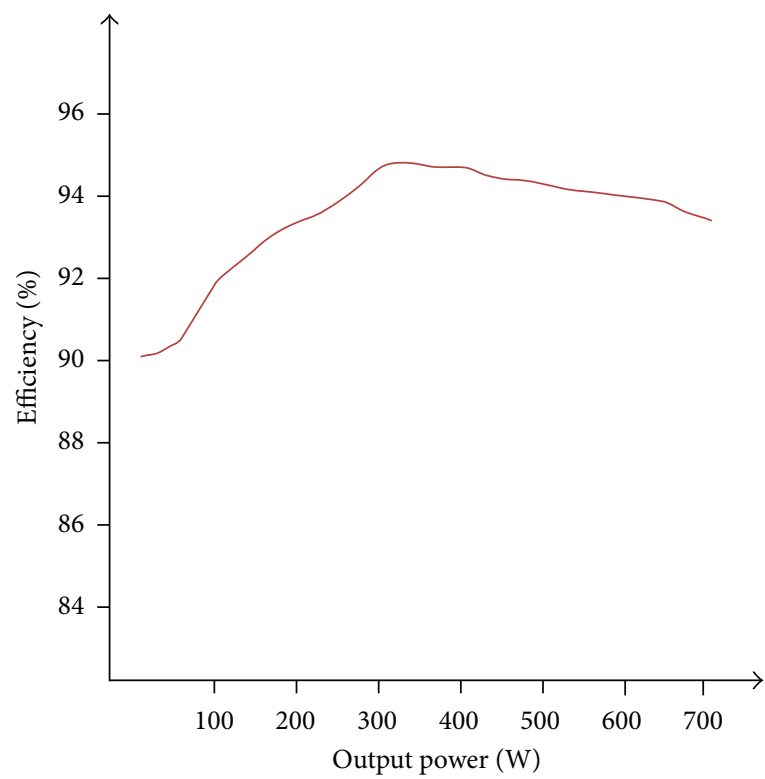

FIgURE 26: The measured efficiency of the proposed MIC.

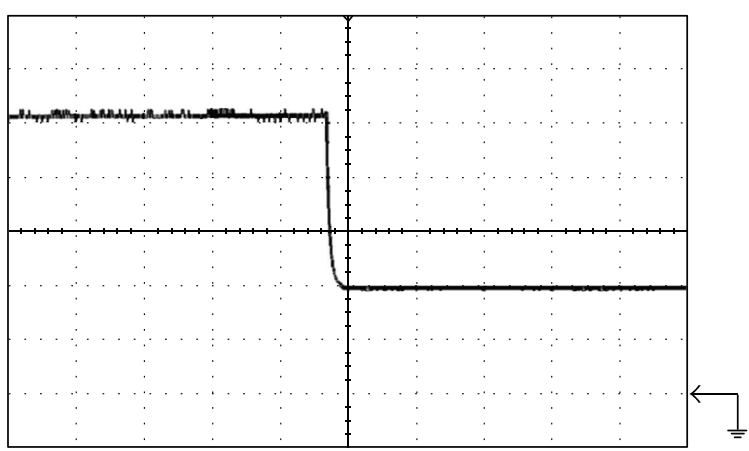

$\left(P_{o}: 100 \mathrm{~W} / \mathrm{div}\right.$, time: $\left.10 \mathrm{~ms} / \mathrm{div}\right)$

FIGURE 27: Output power variation while wind turbine shuts down from the hybrid generation system.

\section{Conclusions}

This paper proposed a galvanic isolated multi-input converter to deal with wind turbine energy and solar power with MPPT feature. The converter integrates two forward converters and only uses one output inductor. Therefore, the structure of the proposed MIC can lower the volume of the converter. In addition, the MIC can operate in interleaved mode so that the output current ripple is suppressed significantly. The energy stored in leakage inductor can be recycled, which 


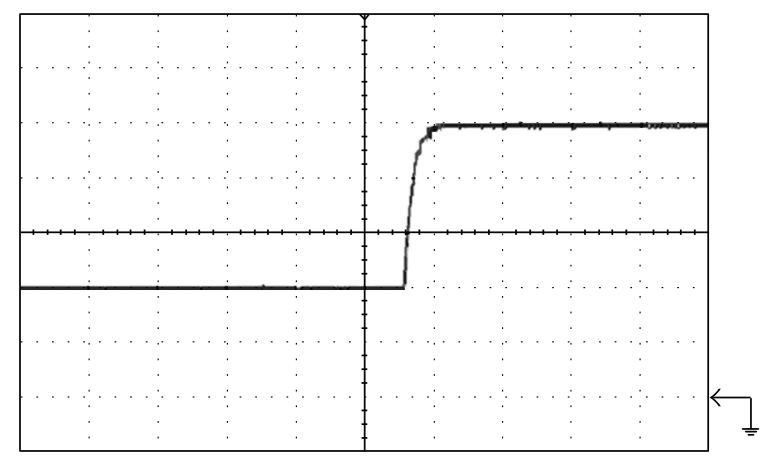

$\left(P_{o}: 100 \mathrm{~W} / \mathrm{div}\right.$, time: $\left.10 \mathrm{~ms} / \mathrm{div}\right)$

FIGURE 28: Output power variation while wind turbine incorporates into the hybrid generation system.

improves efficiency. In this paper, the proposed MIC is analyzed, simulated, and tested. Simulations and hardware measurements have validated the proposed MIC.

\section{References}

[1] R.-J. Wai, W.-H. Wang, and C.-Y. Lin, "High-performance stand-alone photovoltaic generation system," IEEE Transactions on Industrial Electronics, vol. 55, no. 1, pp. 240-250, 2008.

[2] C.-L. Shen and J.-C. Su, "Grid-connection half-bridge PV inverter system for power flow controlling and active power filtering," International Journal of Photoenergy, vol. 2012, Article ID 760791, 8 pages, 2012.

[3] R. Gules, J. D. P. Pacheco, H. L. Hey, and J. Imhoff, "A maximum power point tracking system with parallel connection for PV stand-alone applications," IEEE Transactions on Industrial Electronics, vol. 55, no. 7, pp. 2674-2683, 2008.

[4] D. Meneses, O. García, P. Alou, J. A. Oliver, R. Prieto, and J. A. Cobos, "Single-stage grid-connected forward microinverter with constant off-time boundary mode control," in Proceedings of the 27th Annual IEEE Applied Power Electronics Conference and Exposition (APEC '12), pp. 568-574, February 2012.

[5] Z. Liang, R. Guo, J. Li, and A. Q. Huang, "A high-efficiency PV module-integrated DC/DC converter for PV energy harvest in FREEDM systems," IEEE Transactions on Power Electronics, vol. 26, no. 3, pp. 897-909, 2011.

[6] X. Yuan, J. Chai, and Y. Li, "A transformer-less high-power converter for large permanent magnet wind generator systems," IEEE Transactions on Sustainable Energy, vol. 3, no. 3, pp. 318329, 2012.

[7] B. Singh and S. Sharma, "Design and implementation of fourleg voltage-source-converter-based VFC for autonomous wind energy conversion system," IEEE Transactions on Industrial Electronics, vol. 59, no. 12, pp. 4694-4703, 2012.

[8] R. Li and D. Xu, "Parallel operation of full power converters in permanent-magnet direct-drive wind power generation system," IEEE Transactions on Industrial Electronics, vol. 60, no. 4, pp. 1619-1629, 2013.

[9] F. Deng and Z. Chen, "Control of improved full-bridge threelevel DC/DC converter for wind turbines in a DC grid," IEEE Transaction on Power Electronics, vol. 28, no. 1, pp. 314-324, 2013.

[10] W. Chen, A. Q. Huang, C. S. Li, G. Y. Wang, and W. Gu, "Analysis and comparison of medium voltage high power
DC/DC converters for offshore wind energy systems," IEEE Transaction on Power Electronics, vol. 28, no. 4, pp. 2014-2023, 2013.

[11] N. Vazquez, A. Hernandez, C. Hernandez, E. Rodríguez, R. Orosco, and J. Arau, "A double input DC/DC Converter for photovoltaic/wind systems," in Proceedings of the 39th IEEE Annual Power Electronics Specialists Conference (PESC '08), pp. 2460-2464, June 2008.

[12] Y.-M. Chen, Y.-C. Liu, S.-C. Hung, and C.-S. Cheng, "Multiinput inverter for grid-connected hybrid PV/wind power system," IEEE Transactions on Power Electronics, vol. 22, no. 3, pp. 1070-1077, 2007.

[13] Y.-M. Chen, Y.-C. Liu, and F.-Y. Wu, "Multi-input dc/dc converter based on the multiwinding transformer for renewable energy applications," IEEE Transactions on Industry Applications, vol. 38, no. 4, pp. 1096-1104, 2002.

[14] C.-L. Shen, C.-T. Tsai, Y.-E. Wu, and C.-C. Chen, "A modifiedforward multi-input power converter for solar energy and wind power generation," in Proceedings of International Conference on Power Electronics and Drive Systems (PEDS '09), pp. 631-636, January 2009. 

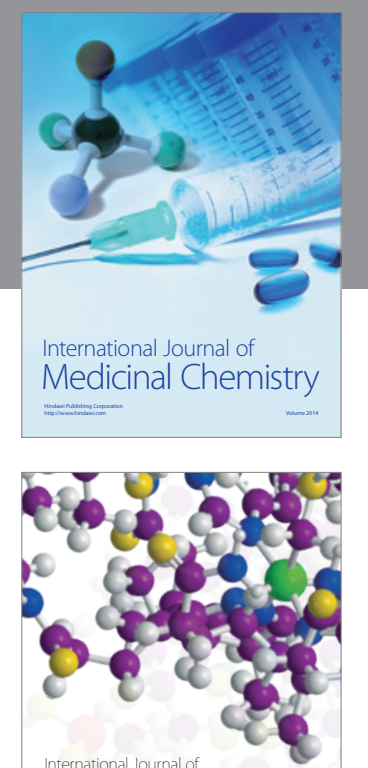

\section{Carbohydrate} Chemistry

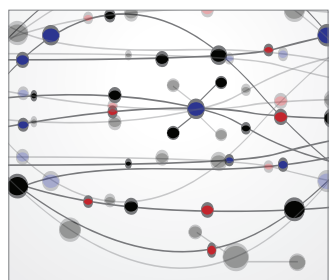

The Scientific World Journal
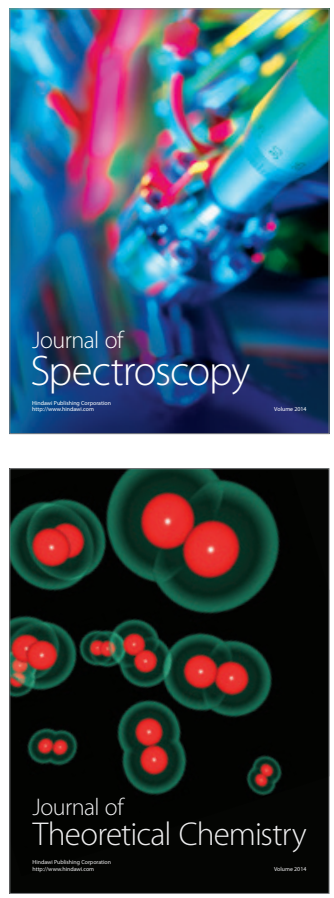
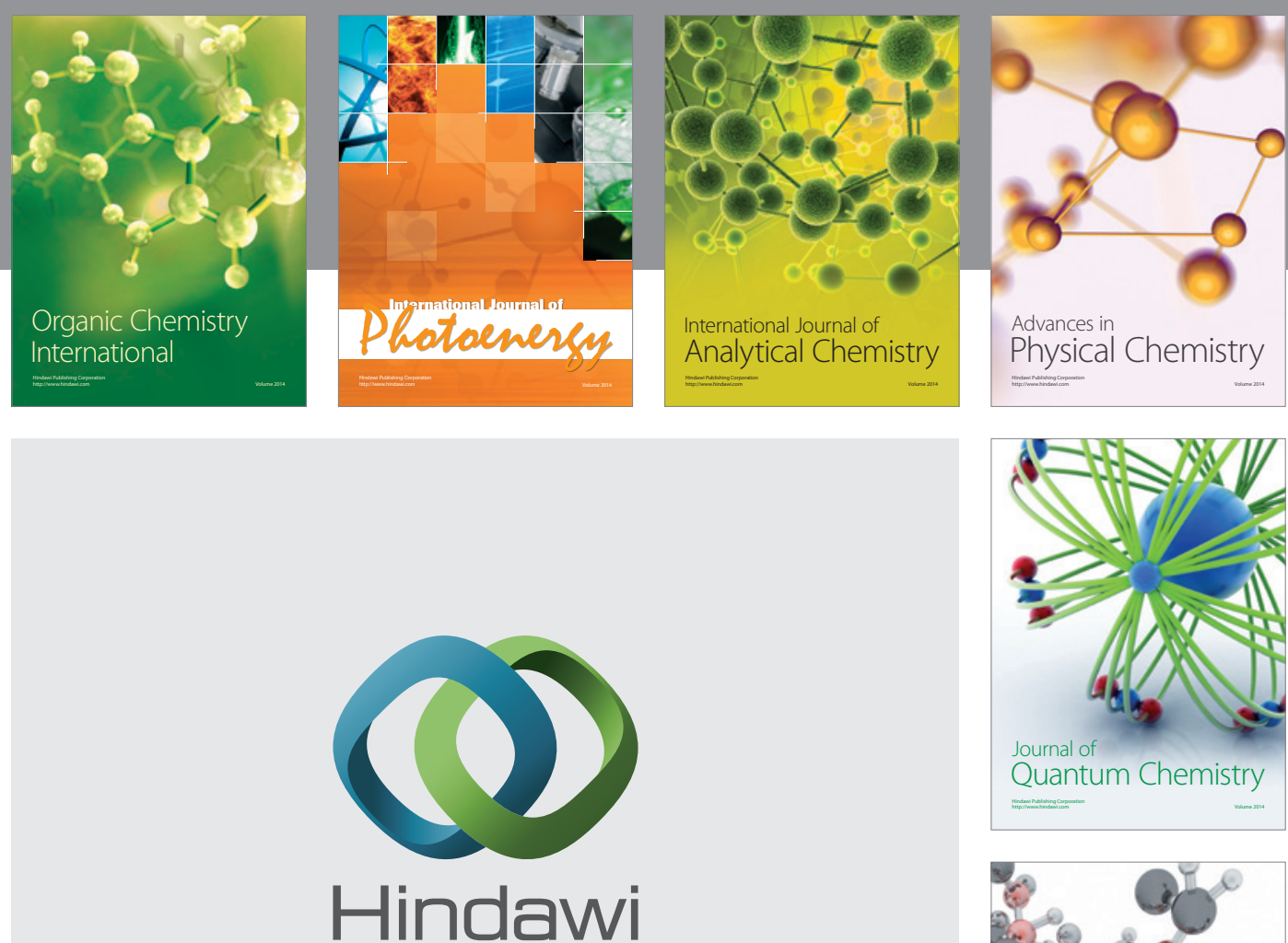

Submit your manuscripts at

http://www.hindawi.com

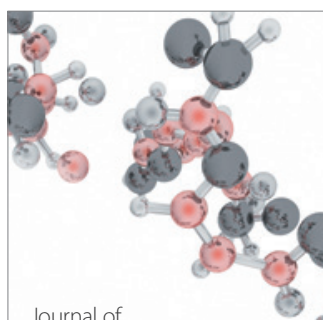

Analytical Methods

in Chemistry

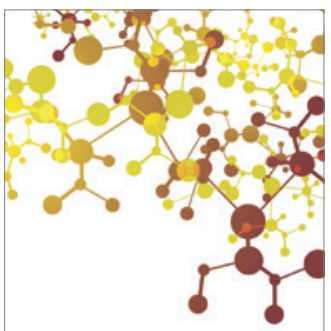

Journal of

Applied Chemistry

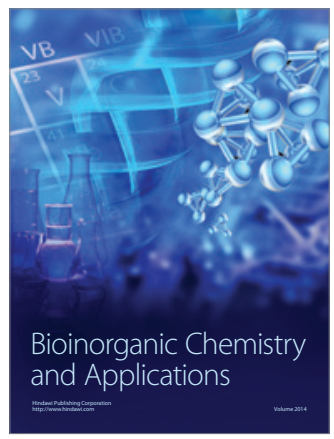

Inorganic Chemistry
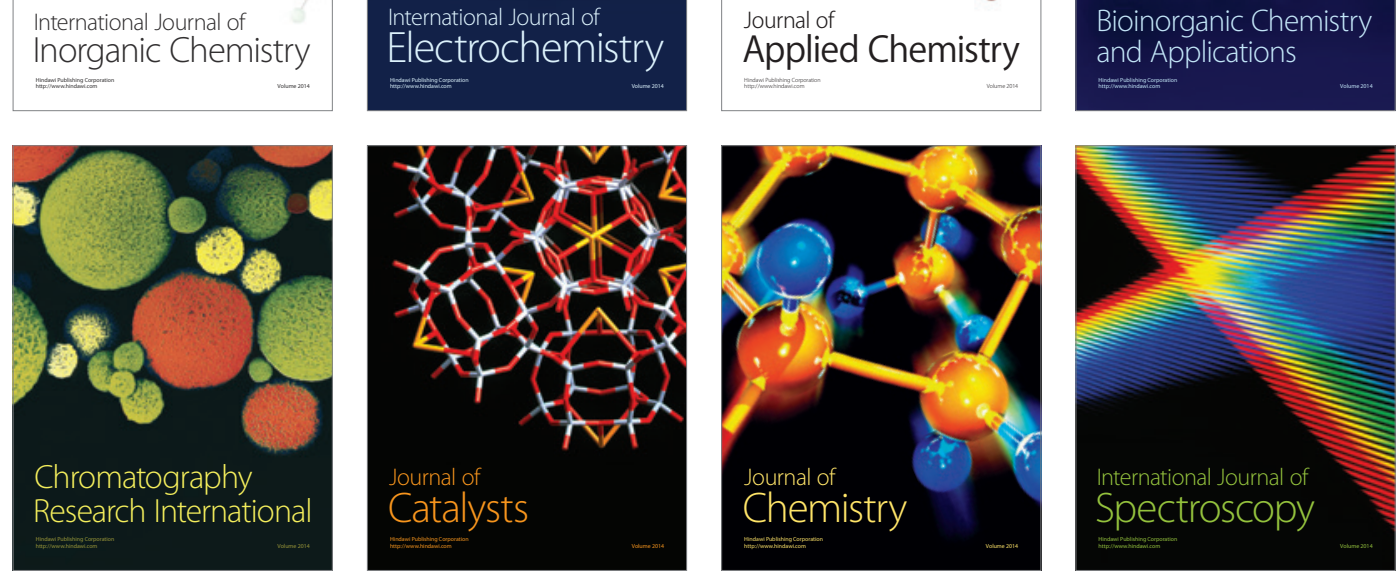